\title{
Produtividade e rentabilidade do abacaxizeiro orgânico em diferentes arranjos de plantio e manejo da vegetação espontânea
}

Jonathas Vasconcelos de Melo ${ }^{1}$, Sebastião Elviro de Araújo Neto ${ }^{*}$, Thays Lemos Uchôa ${ }^{1}$, Leonardo Barreto Tavella ${ }^{1}$

RESUMO: O objetivo deste trabalho foi avaliar a produtividade, a classificação, e a rentabilidade do abacaxizeiro cultivado em sistema orgânico de baixo uso de insumo com diferentes arranjos de plantio e manejo da vegetação espontânea. O experimento foi instalado em área de pousio com vegetação espontânea, com plantio direto das mudas. O delineamento experimental foi o em blocos casualizados em arranjo de parcelas subdivididas com dois tratamentos adicionais. Os fatores alocados às parcelas e às subpacelas foram, respectivamente o tipo de manejo da vegetação espontânea (roçadeira motorizada; capina à tração animal) e o arranjo de plantio (linhas simples, dupla e tripla), com quatro repetições, e 48 plantas por subparcela. Os tratamentos adicionais constituíram de cobertura do solo com filme de polietileno branco ou preto. A produtividade, massa média do fruto e a rentabilidade não se alteram independentemente do tipo de manejo da vegetação espontânea e do arranjo de plantio, e resultou em lucro supernormal.

Palavras-chave: Ananas comosus, cultivo orgânico, plantas espontâneas.

\section{Yield and profitability of organic pineapple in different arrangements of planting and management of spontaneous plants}

\begin{abstract}
The objective of this study was to evaluate the yield, classification and profitability of pineapple crop in organic system with different arrangements of planting and management of spontaneous plants. The experiment was installed in a fallow area with spontaneous plants and direct planting of the seedlings. The experimental design was a randomized complete block design with two additional treatments. The factor assigned to the main and split plots consisted of the type of spontaneous plants management (motorized brush cutter, animal traction weeding) and the planting arrangements (single, double and triple lines), respectively, with four replicationsand 48 plants/split-plot. Additional treatments consisted of triple line planting with soil cover with white or black polyethylene film. The productivity, average fruit mass and profitability did not change with the type of spontaneous plants management and planting arrangement, and resulted in supernormal profit.

Keywords: Ananas comosus. Organic farming, spontaneous plants.
\end{abstract}

\section{INTRODUÇÃO}

O abacaxi (Ananas comosus (L.) Merril) é considerado uma das frutas tropicais mais importantes no mercado mundial. Encontra-se difundido em regiões tropicais e subtropicais, sendo os principais países produtores Tailândia, Costa Rica, Brasil e Filipinas (MELO et al., 2006).

A área colhida no Brasil em 2015 foi de 62.700 hectares, com rendimento médio de 26.733 frutos ha ${ }^{-1}$ (IBGE, 2015). No Acre a área colhida foi de 536 hectares e o rendimento de 14.028 frutos $\mathrm{ha}^{-1}$. Os municípios de Rio Branco, Bujari, Porto Acre, e Capixaba obtiveram as maiores produtividades (IBGE, 2014).

Apesar de ser adaptado às condições tropicais, a produtividade do abacaxizeiro pode ser favorecida pela aplicação de fertilizantes e água e pelo controle da vegetação espontânea (ARAÚJO NETO et al., 2014).

O arranjo de plantio adotado é importante pois influencia diretamente no manejo, na produtividade, na massa média dos frutos e consequentemente no custo de produção. No Brasil, o abacaxizeiro pode ser plantado em fileiras simples, duplas ou triplas (SOUZA et al., 2009). A escolha da melhor disposição das plantas deve considerar o retorno econômico proporcionado pela cultura (SILVA et al., 2012).

A inovação tecnológica não implica somente na aquisição de insumos modernos, mas também na gestão do conhecimento (VIEIRA FILHO et al., 2016). Os tratos culturais e o manejo de pragas, doenças e vegetação espontânea elevam significativamente os custos de produção de abacaxi. Portanto, a elevação dos níveis técnicos, de planejamento e de gestão na fruticultura, desde as etapas de seleção, implantação e condução das culturas, visando maximizar os resultados, é fundamental para $o$ avanço da fruticultura (BAHIENSE et al., 2015).

Em sistema orgânico de produção, os herbicidas sintéticos são proibidos, e podem ser substituídos pelo cultivador de tração animal ou roçadeira costal, entre as linhas de plantio, e por capinas manuais, entre as plantas (ARAÚJO NETO et al., 2014; CUSTÓDIO et al., 2016). 
O objetivo deste trabalho foi avaliar a produtividade, classificação e rentabilidade do abacaxizeiro cultivado em sistema orgânico com diferentes arranjos de plantio e manejo da vegetação espontânea.

\section{MATERIAL E MÉTODOS}

O experimento foi conduzido no Sítio Ecológico Seridó $\left(9^{\circ} 53^{\prime} 16^{\prime}\right.$ 'S e $67^{\circ} 49^{\prime} 11^{\prime}$ ' W, $150 \mathrm{~m}$ de altitude), em Rio Branco - AC. A implantação do experimento foi em março de 2012, e os dados dos custos e da produção foram coletados durante os 1617 meses do ciclo da cultura.

$\mathrm{O}$ experimento foi instalado em área de pousio com Brachiaria brizantha e Urena lobata L. (carrapicho). O preparo da área foi realizado com roçadeira costal motorizada, e carpido com enxada manual na linha de plantio entre as plantas na linha.

A cultivar de abacaxizeiro utilizado foi a RBR-1 (Rio Branco). Após a ceva de quatro meses, as mudas foram plantadas manualmente com auxílio de "espeque" (vara de madeira pontiaguda). Nesta ocasião, as mudas do tipo filhote apresentavam massa média de $545 \pm 55 \mathrm{~g}$.

A análise química do solo na camada de $0-20 \mathrm{~cm}$ de profundidade apresentou os seguintes resultados: $\mathrm{pH}\left(\mathrm{CaCl}_{2}\right)=3,8 ; \mathrm{MO}=18 \mathrm{~g} \mathrm{dm}^{-3} ; \mathrm{P}=2 \mathrm{mg} \mathrm{dm}^{-3} ;$ $\mathrm{K}=2,0 \mathrm{mmolc} \mathrm{dm}^{-3} ; \mathrm{Ca}=17 \mathrm{mmolc} \mathrm{dm}^{-3}$ e $\mathrm{Mg}=8$ mmolc dm ${ }^{-3} ; \mathrm{H}+\mathrm{Al}=42$ mmolc $\mathrm{dm}^{-3} ; \mathrm{Al}=3$ mmolc $\mathrm{dm}^{-3} ; \mathrm{SB}=27,0$ mmolc $\mathrm{dm}^{-3} ; \mathrm{CTC}=69,0$ mmolc $\mathrm{dm}^{-3}$ e V\% $=39,1$.

A parcela principal foi constituída pelo tipo de manejo da vegetação espontânea (roçadeira motorizada; capina à tração animal) e as subparcelas pelo arranjo de plantio (linhas simples, dupla e tripla), com quatro repetições, sendo a unidade experimental composta de 48 plantas cada. Os dois tratamentos adicionais constituíram de plantio em linha tripla e cobertura do solo com filme de polietileno branco/preto e foram colocados em cada parcelas, Constituindo um tratamento adicional.

A indução floral foi realizada no $14^{\circ}$ mês após o plantio, utilizando aplicando-se com pulverizador costal, sob pressão constante, $5 \mathrm{ml}$ da solução de uréia 2\% (20g de uréia/litro de água) e Ethrel a $0,15 \%$ na roseta floral de cada planta (CUSTÓDIO et al., 2016), sendo a colheita finalizada 6 meses após a indução floral.

Para o controle da broca do fruto, 15 dias após a indução floral foi aplicado Bacillus thuringiensis em sua forma comercial Dipel®, $500 \mathrm{~g} \mathrm{ha}^{-1}$, com aplicações quinzenais do florescimento à maturação.

A unidade experimental (sub-parcela) (Figura 1; Tabela 1) foi composta por 48 plantas, constituída por três conjuntos de linhas triplas, linhas duplas e cinco conjuntos de linhas simples para os arranjos linha tripla, dupla e simples respectivamente, sendo cada conjunto separado um do outro pela distancia de um metro. Em cada lateral, um conjunto de linha simples, dupla e tripla e as plantas das extremidades de cada linha, constituíram as bordaduras das subparcelas e a (s) linha (s) central (is) como parcela útil.

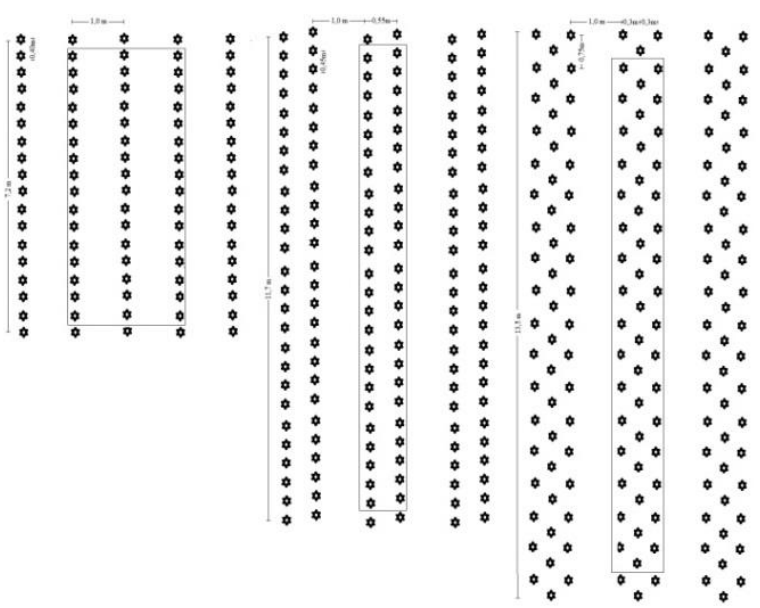

Figura 1. Croqui de uma unidade experimental (subparcela) para cada arranjo de plantio, linha simples (esquerda), linha dupla (central) e linha tripla (direita).

Tabela 1. Manejo da vegetação espontânea, arranjos de plantio, espaçamento (m) e densidade de plantio (plantas ha ${ }^{-1}$ ) dos tratamentos na área experimental, no Sítio Seridó, Rio Branco - Acre, 2012

\begin{tabular}{lccc}
\hline Manejo & Arranjo & Espaçamento $(\mathrm{m})$ & Densidade de plantio \\
\hline Roçadeira ou cultivador & Simples & $1,00 \times 0,40$ & 25.000 \\
Roçadeira ou cultivador & Duplo & $1,00 \times 0,45 \times 0,5517$ & 25.000 \\
Roçadeira ou cultivador & Triplo & $1,00 \times 0,30 \times 0,30 \times 0,75$ & 25.000 \\
Roçadeira ou cultivador & Mulching/triplo & $1,00 \times 0,30 \times 0,30 \times 0,75$ & 25.000 \\
\hline
\end{tabular}


A massa média do fruto foi aferida em balança eletrônica, considerando a infrutescência e a coroa. A produtividade do abacaxizeiro foi determinada pela multiplicação da massa média dos

frutos colhidos na parcela experimental pelo número total de frutos, estimado para $\mathrm{kg} \mathrm{ha}^{-1}$.

Os dados das precipitações pluviométricas no município de Rio Branco, AC, coletados na Estação Meteorológica da Universidade Federal do Acre, no período de janeiro a dezembro de 2012 foram: 402, 452, 317, 163, 127, 182, 63, 97, 52, 189, $372,244 \mathrm{~mm}$, com total anual de $2660 \mathrm{~mm}$; e de janeiro a dezembro de 2013 foram: 410, 217, 411, $70,30,138,50,48,81,157,241,284 \mathrm{~mm}$, com total anual de $2137 \mathrm{~mm}$.

\section{Análise econômica}

Para a análise econômica, foram utilizados os parâmetros de investimento fixo, custos fixo, variável e total, depreciação, relação benefício custo, receita líquida, margem de lucro, remuneração da mão de obra familiar e índice de rentabilidade, conforme metodologia descrita pela Empresa Brasileira de Pesquisa Agropecuária e Serviço Brasileiro de Apoio às Micro e Pequenas Empresas (2003).

O custo de produção, considerando a soma de todos os valores de insumos e serviços, além dos custos alternativos e de oportunidade, foram obtidos in loco, ao longo de todas as etapas na área experimental, Reis (2007).

\section{Custo fixo}

$\mathrm{O}$ custo fixo (CF) refere-se aos recursos que exigem desembolso monetário por parte da atividade produtiva para sua recomposição, como as depreciações dos investimentos fixos e o respectivo custo alternativo. Representa a necessidade de mão de obra ou custos administrativos, englobando os encargos sociais. Independe do aumento ou da queda do volume da produção ou das vendas do empreendimento.

A depreciação (D) é o custo necessário para substituir os bens de capital quando tornados inúteis, seja pelo desgaste físico, seja pelo econômico. Considera-se a depreciação da roçadeira (10 anos) e do cultivador (15 anos). O método empregado foi o linear, referente a cada cultivo, que pode ser mensurado pela equação:

$$
\mathrm{D}=\mathrm{Va}-\operatorname{Vr} \times \mathrm{P}
$$

$\mathrm{D}$ - depreciação, R $\$$ /cultivo; Va - valor atual do recurso, $\mathrm{R} \$$; Vr - valor residual (o valor de revenda ou valor final do bem, após ser utilizado de forma racional na atividade), $\mathrm{R} \$ ; \mathrm{Vu}$ - vida útil (período em ciclos que o bem é utilizado na atividade), e P período considerado, ciclo produtivo.

A análise econômica consistiu de: custo de produção, análise econômica simplificada, receita líquida (REIS, 2007; ARAÚJO NETO et al., 2012). Nessa análise, pode-se encontrar diversas condições, dependendo da posição do preço em relação aos custos, e cada qual sugerindo uma interpretação, definida pelos indicadores econômicos obtidos. Este estudo apresenta-se ao fruticultor agroecológico como um diagnóstico econômico-financeiro de um ciclo da cultura, com respeito à remuneração obtida, à cobertura dos recursos de curto (custos variáveis) e longo (custos fixos) prazos, à comparação entre a remuneração obtida pela atividade produtiva e aquela que seria proporcionada por outras alternativas de aplicação de recursos (REIS, 2007).

\section{Custo variável}

O valor da mão de obra foi considerado o pagamento em diária, calculada considerando o pagamento assalariado de um trabalhador rural com salário mínimo, incluindo mais $12 \%$ de INSS, $8 \%$ de FGTS, $13^{\circ}$ salário, adicional de férias, seguro e salário educação, representando, 45,59\% sobre o salário (CONAB, 2010) divididos por 260 dias de trabalho por ano. Considerando o valor do salário mínimo de R \$ 622,00 em 2012 e de R \$ 724,00 em 2013, o valor da diária resultará em $\mathrm{R} \$ 41,80 / \mathrm{HD}$ e $\mathrm{R} \$ 48,65 / \mathrm{HD}$ para os respectivos períodos, valores acima da diária paga na região que varia de $\mathrm{R} \$ 20,00$ a $\mathrm{R} \$ 30,00$. Portanto, adotou-se o valor equivalente ao salário mínimo pelo fato da agricultura orgânica preconizar justiça social.

$\mathrm{O}$ custo da muda de abacaxizeiro foi calculado como a mão de obra contratada para a coleta e transporte das mesmas para o local de plantio, com rendimento de 600 mudas por homem dia.

\section{Custo alternativo ou de oportunidade}

Para efeito da análise do custo de oportunidade dos recursos alocados na produção, a taxa de juros a ser escolhida para o cálculo do custo de oportunidade foi igual à taxa de retorno da melhor aplicação alternativa. Por ser impossível a determinação deste valor, optou-se pela taxa de juros de $6 \%$ ao ano (a.a.) adotada pela Companhia Nacional de Abastecimento (CONAB, 2010).

\section{Custo total}

O custo total representa a soma de todos os custos com fluxos de serviços de capital (depreciações) e insumos (despesas de custeio), incluindo seus respectivos custos de oportunidade para produzir determinada quantidade do produto. 
O custo total será calculado pela fórmula: $\mathrm{CT}=\mathrm{CF}+\mathrm{CV}$; em que: $\mathrm{CT}$ - custo total; $\mathrm{CF}$ - custo fixo; $\mathrm{CV}$ - custo variável.

\section{Relação custo benefício}

A relação custo benefício (C/B) é definida como o quociente entre o valor atual do fluxo de receitas obtidas e o valor atual do fluxo dos custos, incluindo os investimentos necessários ao desenvolvimento da unidade produtiva. Por este critério, o empreendimento seria descartado caso a RCB fosse menor que 1. Este indicador permite analisar o retorno financeiro para cada unidade monetária de custo do empreendimento durante sua vida útil.

\section{Receita líquida}

A receita líquida é definida pela diferença entre receita total e o custo total. Representa os ganhos obtidos com a atividade incluindo todos os custos. A atividade representaria prejuízo se o resultado fosse inferior ao custo total.

\section{Margem de lucro}

A margem de lucro é o indicador de eficiência operacional do empreendimento. Este índice indica qual é o ganho que o agricultor familiar consegue gerar a partir do trabalho que desenvolve.

A margem de lucro foi calculada pela fórmula: $\mathrm{L}$ $=\mathrm{RL} / \mathrm{RT}$ x 100; onde: $\mathrm{L}-$ margem de lucro; RL receita líquida; RT - receita total.

\section{Rentabilidade}

A rentabilidade sobre o investimento determina o grau de atratividade do empreendimento e permite ao agricultor verificar a taxa de retorno do capital investido. Será obtida percentualmente por unidade de tempo e aponta a taxa de retorno no ano.

$\mathrm{O}$ cálculo do índice de rentabilidade (IR) foi obtida pela fórmula: $\mathrm{IR}=\mathrm{RL} /(\mathrm{I}+\mathrm{CG}) \mathrm{x} 100$; onde: $\mathrm{IR}$ índice de rentabilidade; RL - receita líquida; I investimento fixo; $\mathrm{CG}$ - capital de giro.

O capital de giro foi empregado na compra de insumos e serviços de fora da propriedade, tais como embalagens, inseticida biológico dipel, combustível, óleo lubrificante e transporte.

\section{Remuneração da mão de obra familiar}

A RMOF foi estimada pela divisão da renda do trabalho familiar - RTF - pelo número de homem dia (diárias) de mão de obra familiar - HDF utilizados na atividade. Este indicador representa o valor máximo da diária que a atividade pode pagar pelo trabalho familiar.

\section{Receita}

Para calcular a receita, foi considerado o preço de acordo com a massa do fruto, que na região de estudo variou de $\mathrm{R} \$ 1,00$ para frutos $<1,1 \mathrm{~kg}$; $\mathrm{R} \$$ 2,00 para frutos entre $1,1 \mathrm{~kg}$ a $<1,2 \mathrm{~kg} ; \mathrm{R} \$ 3,00$ para frutos com $1,2 \mathrm{~kg}$ a $<1,5 \mathrm{~kg}$ e $\mathrm{R} \$ 4,00$ para frutos $\geq 1,5 \mathrm{~kg}$.

\section{Análise econômica simplificada}

Os cálculos dos indicadores foram adotados de acordo com Reis (2007), que recomenda os seguintes indicadores econômicos: CTMe - custo total médio; CopFMe - custo operacional fixo médio; CopVMe - custo operacional variável médio; CopTMe - custo operacional total médio; RL receita líquida; $\mathrm{RMe}$ - receita média (preço).

Dependendo da relação receita média/custo de produção, a situação econômica se defini como sendo: (1) - lucro super-normal (RMe>CTMe); (2) lucro normal $(\mathrm{RMe}=\mathrm{CTMe})$; (3a) - resíduo positivo (CTMe>RMe>CopTMe); (3b) - resíduo nulo $(\mathrm{RMe}=\mathrm{CopTMe}) ;(3 \mathrm{c})$ - resíduo nulo com cobertura dos custos variáveis e de parte do custo fixo (CopTMe $>\mathrm{RMe}>\mathrm{CopVMe}$ ). (3d) resíduo negativo sem cobertura dos recursos fixos $(\mathrm{RMe}=\mathrm{CopVMe})$ e somente parte dos recursos variáveis; (3e) resíduo negativo, sem cobrir os recursos variáveis ou capital de giro $(\mathrm{RMe}<\mathrm{CopVMe})$.

O lucro supernormal (RMe $>\mathrm{CTMe}$ ), paga todos os recursos aplicados na atividade econômica e proporciona o lucro adicional, superior ao de outros ramos de mercado. A tendência a médio e longo prazo é de expansão e de entrada de novos produtores para a atividade, atraindo investimentos.

O lucro normal $(\mathrm{RMe}=\mathrm{CTMe})$, paga todos os recursos aplicados na atividade em questão. A remuneração é igual à de outras alternativas (custo de oportunidade) e por isso se diz que o lucro é normal. Seria o que o produtor receberia se aplicasse os recursos (insumos e serviços) na alternativa considerada.

Há também a situação de resíduo: a palavra resíduo se refere a alguma remuneração (parte do custo alternativo se positivo) ou representa prejuízo (no caso negativo). Assim, podem-se apresentar situações de resíduo positivo (CTMe>RMe>CopTMe), resíduo nulo (RMe=CopTMe) e resíduo negativo $(\mathrm{RMe}<\mathrm{CopTMe})$. Neste último caso, ainda pode-se ver se está pelo menos cobrindo o CopVMe, que representa os gastos de curto prazo ou o chamado capital de giro.

$\mathrm{O}$ resíduo positivo (CTMe>RMe>CopTMe), paga todos os recursos aplicados na atividade (RMe>CopTMe). A remuneração é menor que a de outras atividades (custo de oportunidade) e, neste caso, o produtor estaria diante de uma situação em que está rendendo menos do que os juros ou aluguel ou de outra base de cálculo para custo alternativo. A tendência é de permanecer na atividade, mas, no 
longo prazo, poderia buscar outras melhores alternativas de aplicação do capital.

$\mathrm{O}$ resíduo nulo $(\mathrm{RMe}=\mathrm{CopTMe})$, paga todos os recursos de produção (RMe=CopTMe). Nesta situação não há remuneração alternativa, ou seja, a atividade deixa de ganhar o equivalente ao custo alternativo. A tendência é de permanecer na atividade, mas poderia abandoná-la se os resultados não melhorarem.

$\mathrm{O}$ resíduo negativo com cobertura de parte do custo fixo (CopTMe>RMe $>\mathrm{CopVMe}$ ), paga os recursos variáveis e parte dos fixos. A tendência a médio e longo prazo é retrair e sair da atividade.

O resíduo é negativo sem cobertura dos recursos fixos $(\mathrm{RMe}=\mathrm{CopVMe})$ e somente parte dos recursos variáveis. A tendência é de sair da atividade.

No resíduo negativo, sem cobrir os recursos variáveis ou capital de giro (Rme<CopVMe), ocorre a necessidade de subsidiar os recursos variáveis. A saída da atividade reduz os prejuízos.

\section{Análise estatística}

Os resultados das variáveis avaliadas foram submetidos à verificação de dados discrepantes Grubbs, normalidade dos resíduos Shapiro e Wilk, homogeneidade de variâncias Bartlett. Os dados foram submetidos à análise de variância pelo teste $\mathrm{F}$ de acordo com um delineamento em blocos casualizados, com 4 repetições de tratamentos, em esquema de parcelas subdivididas de 48 plantas cada sub-parcela. Os tratamentos nas parcelas foram dois tipos de manejo da vegetação espontânea limpeza da vegetação com cultivador a tração animal e roçadeira costal motorizada e os das sub-parcelas foram três arranjos de plantio linha simples, dupla e tripla (Figura 1). Teve dois tratamentos adicionais, composto por solo coberto com filme de polietileno branco ou preto em linha tripla. As médias de tratamentos foram comparadas pelo teste de Dunnett. Também efetuou-se, pelo teste $t$ de Student, a comparação das médias de algumas variáveis com valores de referência e resultados obtidos em outros trabalhos.

\section{RESULTADOS E DISCUSSÃO}

O manejo da vegetação espontânea, o arranjo de plantio e o uso de "mulching" (cobertura do solo com filme de polietileno branco ou preto) (tratamentos adicionais) não interferiram na produtividade, massa média e classificação comercial dos frutos, custo operacional fixo, custo operacional variável, custo operacional total, custo fixo total, custo variável total, custo total, receita total, receita líquida, lucro e no índice de rentabilidade.

A produtividade média do abacaxizeiro foi de 25.502,07 $\mathrm{kg} \mathrm{ha}^{-1}$ (Tabela 2). Esta é decorrente da densidade de 25.000 plantas. A densidade de plantio tem correlação direta com a produtividade, quanto maior a densidade maior produtividade (ARAÚJO NETO et a., 2014; CUSTÓDIO et al., 2016; REIS et al., 2012), mesmo que a massa de cada fruto seja reduzida (SOUZA et al., 2009).

Tabela 2. Massa média dos frutos $\left(\mathrm{g}_{\text {fruto }}{ }^{-1}\right)$ e produtividade média do abacaxizeiro orgânico $\left(\mathrm{kg} \mathrm{ha}^{-1}\right)$ em dois manejos da vegetação espontânea, roçadeira costal motorizada e cultivador com tração animal, em fileiras simples, duplas e triplas. Sítio Seridó, Rio Branco - Acre, 2014

\begin{tabular}{lccc}
\hline Manejo & Arranjos & Produtividade & Massa Média dos Frutos \\
\hline \multirow{3}{*}{ Cultivador } & Simples & $29.114^{\mathrm{ns}}$ & $1,165^{\mathrm{ns}}$ \\
& Duplas & $25.272^{\mathrm{ns}}$ & $0,921^{\mathrm{ns}}$ \\
& Triplas & $23.022^{\mathrm{ns}}$ & $1,061^{\mathrm{ns}}$ \\
\hline \multirow{3}{*}{ Roçadeira } & Simples & $24.527^{\mathrm{ns}}$ & $1,162^{\mathrm{ns}}$ \\
& Duplas & $26.511^{\mathrm{ns}}$ & $1,090^{\mathrm{ns}}$ \\
\hline Cultivador & Triplas & $25.939^{\mathrm{ns}}$ & $1,193^{\mathrm{ns}}$ \\
& Cobertura do solo com & $25.593^{\mathrm{ns}}$ & $1,024^{\mathrm{ns}}$ \\
Roçadeira & filme de polietileno & $24.037^{\mathrm{ns}}$ & $105^{\mathrm{ns}}$ \\
& branco ou preto & & \\
& (Mulching) (triplas) & & \\
\end{tabular}

Não foi aplicado o teste de comparação de médias pois o F não foi significativo.

Não houve diferença significativa entre as médias das parcelas e dos tratamentos adicionais.

Reduzir a utilização de matéria e energia na agricultura, mantendo alto o balanço energético na produção, é um dos princípios da sustentabilidade, gastando o mínimo de energia no processo produtivo, procurando, sempre que possível, utilizar pouco insumo e pouco serviço (mão-de-obra) (FURLANETO et al., 2013).

O manejo da vegetação espontânea na cultura do abacaxi é importante para o aumento de produtividade e da massa média do fruto, pois se trata de uma cultura de pequeno porte que apresenta desenvolvimento vegetativo inicial lento, favorecendo a extração de água e nutrientes pela vegetação espontânea (ARAÚJO NETO et al., 2014; CATUNDA et al., 2005). Este efeito é mais evidente em sistemas de cultivo de alto uso de insumos, em que as plantas crescem rapidamente e necessitam de maiores quantidades de nutrientes, água e luz.

$\mathrm{Na}$ Bahia, capinas a intervalos de um mês proporcionaram frutos de massa superior a $1,3 \mathrm{~kg}$ e a 
intervalos de dois meses a produtividade diminuiu (REINHARDT et al., 1981).

A massa média do fruto foi de $1,090 \mathrm{~kg}$ (Tabela 2). O abacaxi comercial pode ser produzido com massa média de $1,73 \mathrm{~kg}$ (MELO et al., 2006) ou $2,29 \mathrm{~kg}$ (LEONEL et al., 2014). E em sistema orgânico, com massa média de $1,635 \mathrm{~kg}$ (CUSTÓDIO et al., 2016).
A classificação dos frutos comercializados a $\mathrm{R} \$$ $1,00, \mathrm{R} \$ 2,00, \mathrm{R} \$ 3,00$ e $\mathrm{R} \$ 4,00$, distribuídos em $49,13 \%, \quad 24,40 \%, \quad 16,24 \%$ e $10,22 \%$, respectivamente, não foi afetada pelo método de manejo da vegetação espontânea nem pelo arranjo de plantio (Tabela 3).

Tabela 3. Porcentagem (\%) de frutos comercializados a R\$1,00, 2,00, 3,00 e 4,00 reais em dois manejos da vegetação espontânea, roçadeira costal motorizada e cultivador com tração animal, em fileiras simples, duplas e triplas. Sítio Seridó, Rio Branco Acre, 2014

\begin{tabular}{|c|c|c|c|c|c|}
\hline & Arranjos & $\mathrm{R} \$$ & $\mathrm{R} \$ 2,00$ & $\mathrm{R} \$ 3,00$ & $\mathrm{R} \$ 4,00$ \\
\hline \multirow{3}{*}{ Cultivador } & Simples & $34,57^{\mathrm{ns}}$ & $30,81^{\mathrm{ns}}$ & $29,27^{\mathrm{ns}}$ & $5,35^{\mathrm{ns}}$ \\
\hline & Duplas & $72,22^{\mathrm{ns}}$ & $17,22^{\mathrm{ns}}$ & $8,33^{\mathrm{ns}}$ & $2,22^{\mathrm{ns}}$ \\
\hline & Triplas & $55,93^{\mathrm{ns}}$ & $30,17^{\mathrm{ns}}$ & $7,78^{\mathrm{ns}}$ & $6,11^{\mathrm{ns}}$ \\
\hline \multirow{3}{*}{ Roçadeira } & Simples & $42,30^{\mathrm{ns}}$ & $20,80^{\mathrm{ns}}$ & $18,33^{\mathrm{ns}}$ & $18,56^{\mathrm{ns}}$ \\
\hline & Duplas & $50,83^{\mathrm{ns}}$ & $20,90^{\mathrm{ns}}$ & $16,07^{\mathrm{ns}}$ & $12,14^{\mathrm{ns}}$ \\
\hline & Triplas & $38,95^{\mathrm{ns}}$ & $26,47^{\mathrm{ns}}$ & $17,67^{\mathrm{ns}}$ & $16,91^{\mathrm{ns}}$ \\
\hline
\end{tabular}

Cultivador Cobertura do solo com filme de
polietileno branco ou preto (Mulching)
(triplas)

$59,72^{\mathrm{ns}}$

$12,50^{\mathrm{ns}}$

$19,44^{\mathrm{ns}}$

$8,33^{\mathrm{ns}}$

Roçadeira

$48,79^{\mathrm{ns}}$

$26,47^{\mathrm{ns}}$

$11,46^{\mathrm{ns}}$

$14,15^{\mathrm{ns}}$

Não foi aplicado o teste de comparação de médias pois o $\mathrm{F}$ de interação não foi significativo.

Médias que não diferem (ns) significativamente com a média do tratamento adicional "mulching", pelo teste de Dunnett, a 5\% de probabilidade.

Souza et al. (2011) observaram que a competição entre a cultura de valor econômico e a vegetação espontânea em determinado nível pode diminuir a massa do fruto e a produtividade, reduzindo o valor comercial.

O consumidor brasileiro prefere frutos com massa acima de $1,5 \mathrm{~kg}$. Por outro lado, o mercado internacional exige frutos com massa variando entre 0,5 e $1,0 \mathrm{~kg}$, conforme destacado por (SANTANA et al., 2001).

Plantas de abacaxi induzidas tardiamente, com maior acúmulo de reservas produzem frutos com massa superior (GONDIM; AZEVEDO 2002). No entanto, apesar da indução floral neste experimento ter sido realizada aos 14 meses após o plantio, os frutos apresentaram tamanho e massa reduzidos, possivelmente devido à baixa precipitação pluviométrica na fase de reprodução e baixa fertilidade natural do solo, que não recebeu adubação por ser cultivo com baixo uso de insumos.

Outro fator fundamental é a disposição das plantas do pomar, tanto para o manejo como para o melhor aproveitamento da luminosidade. $\mathrm{O}$ arranjo de plantio facilita os tratos culturais, favorece o manejo da vegetação espontânea e maximiza o aproveitamento dos recursos ambientais (ALBUQUERQUE et al., 2012). Todavia, quando a concorrência se eleva ao ponto crítico, as plantas começam a competir pelos recursos disponíveis (ARAÚJO NETO et al., 2014).
A massa do fruto do abacaxizeiro obtido neste estudo foi inferior $(p>0,05)$ aos $1,74 \mathrm{~kg}$ citado por Melo et al. (2006) e 1,77 kg citado por Souza et al. (2007) que depende, entre outros fatores, especialmente do estado nutricional e estádio de crescimento alcançado pela planta quando da diferenciação floral (GONDIM; AZEVEDO, 2002).

Provavelmente, a maior produção de frutos menores $49,13 \%$, comercializados a $\mathrm{R} \$ 1,00$, esteja relacionada com a baixa disponibilidade hídrica no período do verão amazônico e a reduzida fertilidade natural do solo. A baixa massa do fruto possivelmente poderia ser aumentada, neste caso, com a utilização de irrigação (MELO et al., 2006; SOUZA et al., 2007; SOUZA et al., 2009) e de adubação equilibrada (TEIXEIRA et al., 2002; SPIRONELLO et al., 2004; COELHO et al., 2007).

Alguns autores destacam que o uso da irrigação complementar possibilita incremento na produção da cultura (SOUZA et al., 2007). Entretanto, a rentabilidade da cultura nestas áreas diminui, devido aos custos fixos adicionais com aquisição, manutenção e depreciação de equipamentos utilizados em áreas irrigadas, que podem representar mais da metade dos custos de produção da lavoura de abacaxi (PONCIANO et al., 2006).

A rentabilidade econômica de todos os tratamentos neste experimento foi de lucro supernormal, em que a receita total foi maior que o custo total $(\mathrm{RL}>\mathrm{CT})$, que cobre todos os recursos aplicados na atividade econômica, inclusive a 
remuneração do capital empregado (custo de oportunidade). Apesar da baixa produtividade e classificação dos frutos, o preço pago ao abacaxi orgânico na região, aliado ao baixo custo de produção promoveu esta lucratividade. Isto também foi observado por Araújo Neto et al. (2008) em cultivo orgânico de maracujá, por Araújo Neto et al. (2012) em cultivo orgânico de alface, e por Souza et al. (2015) em cultivo orgânico de cebolinha.

O lucro variou de 47,11 a 62,78\% (Tabela 4), superiores $(\mathrm{p}<0,05)$ à remuneração constatada por Barreto et al. (2010), cultivando mamão, e Furlaneto et al. (2011), no cultura do maracujá.

O grau de atratividade do empreendimento, determinado pelo índice de rentabilidade (IR) variou de 104,53 a 204,26 \% (Tabela 4) Araújo Neto et al.
(2008), em cultivos de maracujazeiro-amarelo orgânico no Acre. Desta forma, os valores obtidos neste experimento foram acima do mercado, caracterizando o baixo investimento em custo fixo e variável para esta atividade, influenciada também pelo alto preço da fruta praticado no mercado local.

$\mathrm{O}$ uso intensivo de insumos deve aumentar a produtividade significativamente para que haja retorno econômico, pois mesmo com menor produtividade, o baixo custo de produção pode tornar a produção de abacaxizeiro mais rentável (REIS et al., 2012).

A remuneração da mão de obra familiar variou de $\mathrm{R} \$ 109,23$ dia a $\mathrm{R} \$ 208,50$ dia, superou $(\mathrm{p}>0,05)$ a remuneração paga a trabalhadores rurais na região e o valor da diária considerada neste trabalho.

Tabela 4. Dados da análise econômica da produção orgânica de abacaxi, cv. RBR-1, em dois manejos da vegetação espontânea, cultivador à tração animal e roçadeira costal motorizada e três arranjos de plantio dispostos em fileiras simples, duplas e triplas e o tratamento adicional com cobertura plástica "mulching” em fileiras triplas, Sítio Seridó, Rio Branco - Acre, 2014

\begin{tabular}{|c|c|c|c|c|c|}
\hline \multirow{13}{*}{ CTA } & INDICADOR & SIMPLES & DUPLA & TRIPLA & MULCHING \\
\hline & PD & $29.114,05$ & $25.272,46$ & $23.021,99$ & $25.592,88$ \\
\hline & COPF & 34,59 & 25,01 & 23,58 & 23,01 \\
\hline & COPV & $16.419,34$ & $16.524,73$ & $16.894,96$ & $20.536,46$ \\
\hline & COPT & $16.453,93$ & $16.549,75$ & $16.918,54$ & $20.559,46$ \\
\hline & CFT & 332,56 & 322,40 & 320,89 & 320,28 \\
\hline & CVT & $17.404,50$ & $17.516,22$ & $17.908,65$ & $21.768,64$ \\
\hline & $\mathrm{CT}$ & $17.737,06$ & $17.838,62$ & $18.229,54$ & $17.202,90$ \\
\hline & RT & $51.346,15$ & $35.138,89$ & $41.016,48$ & $44.097,22$ \\
\hline & RL & $33.609,09$ & $17.300,27$ & $22.786,94$ & $26.894,32$ \\
\hline & $\mathrm{L}$ & 62,28 & 47,11 & 51,49 & 55,05 \\
\hline & IR & 204,26 & 104,53 & 134,68 & 130,81 \\
\hline & RMOF & 208,50 & 110,73 & 138,19 & 180,20 \\
\hline \multirow{12}{*}{$\mathrm{RCM}$} & PD & $24.527,01$ & $26.511,68$ & $25.938,99$ & $24.037,54$ \\
\hline & $\mathrm{COPF}$ & 71,36 & 34,59 & 25,01 & 58,08 \\
\hline & COPV & $16.053,67$ & $16.419,34$ & $16.524,73$ & $20.209,72$ \\
\hline & COPT & $16.125,03$ & $16.453,93$ & $16.549,75$ & $20.267,80$ \\
\hline & CFT & 371,54 & 351,49 & 322,40 & 357,46 \\
\hline & CVT & $17.016,89$ & $16.851,41$ & $17.516,22$ & $21.422,30$ \\
\hline & CT & $17.388,43$ & $17.202,90$ & $17.202,90$ & $17.202,90$ \\
\hline & $\mathrm{RT}$ & $49.025,00$ & $40.273,81$ & $45.166,17$ & $42.490,73$ \\
\hline & RL & $31.636,57$ & $23.070,91$ & $27.963,27$ & $25.287,82$ \\
\hline & $\mathrm{L}$ & 62,78 & 51,67 & 60,82 & 56,60 \\
\hline & IR & 196,19 & 140,21 & 168,96 & 124,77 \\
\hline & RMOF & 109,23 & 155,05 & 178,64 & 188,53 \\
\hline
\end{tabular}

$\mathrm{CTA}=$ cultivador à tração animal; $\mathrm{RCM}=$ roçadeira costal motorizada; $\mathrm{PD}=$ produtividade $\left(\mathrm{kg} \mathrm{ha}^{-1}\right) ; \mathrm{COPF}=$ custo operacional fixo ( $\mathrm{R} \$ / \mathrm{dia})$; $\mathrm{COPV}=$ custo operacional variável $(\mathrm{R} \$ / \mathrm{ha}) ; \mathrm{COPT}=\mathrm{Custo}$ operacional total $(\mathrm{R} \$ / \mathrm{ha}) ; \mathrm{CFT}=$ custo fixo total $(\mathrm{R} \$ / \mathrm{ha}) ; \mathrm{CVT}=$ custo variável total $(\mathrm{R} \$ / \mathrm{ha}) ; \mathrm{CT}=$ custo total $(\mathrm{R} \$ / \mathrm{ha}) ; \mathrm{RT}=$ receita total $(\mathrm{R} \$ / \mathrm{ha}) ; \mathrm{RL}=$ receita líquida $(\mathrm{R} \$ / \mathrm{ha}) ; \mathrm{L}=\mathrm{lucro}(\%) ; \mathrm{IR}=$ índice de rentabilidade (\%); RMOF= remuneração da mão de obra familiar (R\$/ha).

\section{CONCLUSÕES}

O cultivo orgânico de abacaxizeiro com baixo uso de insumos pode ter a vegetação espontânea manejada com roçadeira costal motorizada ou com cultivador à tração animal independentemente do arranjo de plantio em linhas simples, dupla ou tripla, que não altera a produtividade e a massa do fruto, proporcionando lucro supernormal.

\section{AGRADECIMENTO}

À Coordenação de Aperfeiçoamento de Pessoal de Nível Superior (CAPES) e ao Conselho Nacional de Desenvolvimento Científico e Tecnológico (CNPq) pela concessão de bolsa aos autores.

\section{REFERÊNCIAS}

ALBUQUERQUE, C. J. B.; TARDIN, F. D.; PARRELlA, R. A. da C.; GUIMARÃES, A. de S.; OLIVEIRA, R. M. de; SILVA, K. M. de J. Sorgo sacarino em diferentes arranjos de plantas e localidades de Minas Gerais, Brasil. Revista Brasileira de Milho e Sorgo, v. 11, n. 1, p. 69-85, 2012. 
ARAÚJO NETO, S. E. de; CAMPOS, P. A.; TAVELLA, L. B.; SOLINO, A. J. da S.; SILVA, I. F. da. Organic polyculture of passion fruit, pineapple, corn and cassava: the influence of green manure and distance between espaliers. Ciência e Agrotecnologia, v. 38, n. 3, p. 247 255,2014

ARAÚJO NETO, S. E. de; FERREIRA, R. L. F.; PONTES, F. S. T.; NEGREIROS, J. R. da S. Rentabilidade econômica do maracujazeiro-amarelo plantado em covas e em plantio direto sob manejo orgânico. Revista Brasileira de Fruticultura, v. 30, n. 4, p. $940-945$, dez. 2008.

ARAÚJO NETO, S. E. de; SILVA, E. M. N. C. de P. da; FERREIRA, R. L. F.; CECÍLIO FILHO, A. B. Rentabilidade da produção orgânica de alface em função do ambiente, preparo do solo e época de plantio. Revista Ciência Agronômica, v .43, n. 4, p.783 - 791, 2012.

BAHIENSE, D. V.; SOUZA, P. M. de; PONCIANO, N J. Incentivos à produção de frutas e as mudanças na agricultura da região norte do estado do Rio de Janeiro. Revista Brasileira de Fruticultura, v. 37 , n. 2, p. $387-$ $395,2015$.

BARRETO, H. B. F.; COSTA, E. M. da; OLIVEIRA, D. M. de; SILVA, K. B. da; ARAÚJO, J. A. de M. Custos de produção e rentabilidade do cultivo do mamão formosa (Tainung $\mathrm{n}^{\circ}$ 1) na cidade de Baraúna-RN. Revista Verde de Agroecologia e Desenvolvimento Sustentável, v. 5, n. 2, p. 96-102, 2010.

CATUNDA, M. G.; FREITAS, S. P.; OLIVEIRA, J. G.; SILVA, C. M. M. Efeitos de herbicidas na atividade fotossintética e no crescimento de abacaxi. Plantas Daninhas, v. 23, n. 1, p. 115-121, 2005.

COELHO, R. I.; LOPES, J. C.; CARVALHO, A. J. C. de; AMARAL, J. A. T. de; MATTA, F. de P. Estado nutricional e características de crescimento do abacaxizeiro "Jupi" cultivado em Latossolo Amarelo distrófico em função da adubação com NPK. Ciência e Agrotecnologia, v. 31, n. 6, p. 1696-1701, 2007.

CONAB. Companhia Nacional de Abastecimento. Custo de produção agrícola: a metodologia da Conab. Brasília, 2010. p. 60.

CUSTÓDIO, R. A.; ARAÚJO NETO, S. E. de; FERMINO JUNIOR, P. C. P.; ANDRADE NETO, R. de C.; SILVA, I. F. Morpho-anatomy of leaves and yield of pineapple plant in intercropping with cassava. Bioscience Journal, v. 32, n. 4, p. 839 - 848, 2016.

EMPRESA BRASILEIRA DE PESQUISA AGROPECUÁRIA; SERVIÇO BRASILEIRO DE APOIO ÀS MICRO E PEQUENAS EMPRESAS. Iniciando um pequeno grande negócio agroindustrial: frutas desidratadas. Brasília: Embrapa Informação Tecnológica, 2003. 115 p. (Série Agronegócios).

FURLANETO, F. de P. B.; ESPERANCINI, M. S. T.; BUENO, O. de C.; MARTINS, A. N.; VIDAL, A. de A. Custo energético da produção do maracujazeiro amarelo na região de Marília. Energia na Agricultura, v. 28, n. 1, p.57-64, 2013.

FURLANETO, F. de P. B.; MARTINS, A. N.; ESPERANCINI, M. S. T.; VIDAL, A. de A.; OKAMOTO, F. Custo de produção do maracujá-amarelo (Passiflora edulis). Revista Brasileira de Fruticultura, v. 33, n. spe, p. 441-446,2011.

GONDIM, T. M. de S.; AZEVEDO, F. F. Diferenciação floral do abacaxizeiro cv. SNG-3 em função de idade da planta e da aplicação do carbureto de cálcio. Revista Brasileira de Fruticultura, v. 24, n. 2, p. 420-425, 2002.

IBGE. Instituto Brasileiro de Geografia e Estatistica. Produção agrícola municipal: culturas temporárias e permanentes. 2014. Disponível em: < http://www.ibge. gov.br/home/estatistica/indicadores/agropecuaria/lspa/>. Acesso em 10 set. 2014.

IBGE. Instituto Brasileiro de Geografia e Estatistica. Produção agrícola municipal: culturas temporárias e permanentes. 2015. Disponível em: <ftp://ftp.ibge.gov. br/Producao_Agricola/Levantamento_Sistematico_da_Pr oducao_Agricola_[mensal]/Fasciculo/lspa_201605.pdf $>$. Acesso em15 jul. 2016.

LEONEL, S.; LEONEL, M.; SAMPAIO, A. C. Processamento de frutos de abacaxizeiro cv. Smooth Cayenne: perfil de açúcares e ácidos dos sucos e composição nutricional da farinha de cascas. Revista Brasileira de Fruticultura, v. 36, n. 2, p. 433-439, jun. 2014.

MELO, A. S. de; AGUIAR NETTO, A. de O.; DANTAS NETO, J.; BRITO, M. E. B.; VIÉGAS, P. R. A.; MAGALHÃES, L. T. S.; FERNANDES, P. D. Desenvolvimento vegetativo, rendimento da fruta $\mathrm{e}$ otimização do abacaxizeiro cv. Pérola em diferentes níveis de irrigação. Ciência Rural, v. 36, n. 1, p. 93-98, 2006.

PONCIANO, N. J.; CONSTANTINO, C. O. R.; SOUZA, P. M. de; DETMANN, E. Avaliação econômica da produção de abacaxi (Ananas comosus L.) cv. Pérola na região norte fluminense. Revista Caatinga, v. 19, n. 1, p. 82-91, 2006.

REINHARDT, D. H. R. C.; SANCHES, N. F.; CUNHA, G. A. P. da; Métodos de controle de ervas daninhas na cultura do abacaxizeiro. Pesquisa Agropecuária Brasileira, v. 16, n. 5, p. 719-24, 1981.

REIS, L. L. dos; TARSITANO, M. A. A.; HIRAKI, S. S.; BARDIVIESSO, D. M. Custo de produção e rentabilidade de abacaxizeiro cv. Pérola em Cassilândia 
(MS), sob diferentes doses de potássio. Bioscience Journal, v. 28, n. 5, p. 725-733, 2012.

REIS, R. P. Fundamentos de economia aplicada. Lavras: UFLA/FAEPE, 2007. 95 p. Texto Acadêmico.

SANTANA, L. L. de A. REINHARDT, D. H.; CUNHA, G. A. P. da; CALDAS, R. C.; Altas densidades de plantio na cultura do abacaxi cv. Smooth Cayenne, sob condições de sequeiro. Revista Brasileira de Fruticultura, v. 23, n. 2, p. 353-358, 2001.

SILVA, V. A.; LIMA, L. A.; ANDRADE, F. T.; FERREIRA, E. A.; SOUZA JÚNIOR, E. A. de; COLARES, M. F. B.; MOREIRA, L. L. Q. Sistemas intercalares com abacaxizeiro como alternativa de renda durante a formação de cafezais irrigados. Pesquisa Agropecuária Brasileira, v. 47, n. 10, p. 1471-1479, 2012.

SOUZA, B. P.; SIMOES, A. C.; ALVES, G. E. B.; FERREIRA, R. L. F.; ARAÚJO NETO, S. E. de. Produtividade e rentabilidade de cebolinha orgânica sob diferentes densidades de plantio e métodos de colheita. Enciclopédia Biosfera, v. 11, p. 1576-1585, 2015.

SOUZA, C. B. de; SILVA, B. B. da; AZEVEDO, P. V. de. Crescimento e rendimento do abacaxizeiro nas condições climáticas dos tabuleiros costeiros do Estado da Paraíba. Revista Brasileira de Engenharia Agrícola e Ambiental, v. 11, n. 2, p.134-41, 2007.
SOUZA, O. P. de; TEODORO, R. E. F.; MELO, B. de; TORRES, J. L. R. Qualidade do fruto e produtividade do abacaxizeiro em diferentes densidades de plantio e lâminas de irrigação. Pesquisa Agropecuária Brasileira, v. 44, n. 5, p. 471-477, 2009.

SOUZA, O. P. de; TORRES, J. L. R. Caracterização física e química do abacaxi sob densidades de plantio e lâminas de irrigação no triângulo mineiro. Magistra, v. 23, n. 4, p. 175-185, 2011.

SPIRONELlO, A.; QUAGGIO, J. A.; TEIXEIRA, L. A. J.; FURLANI, P. R.; SIGRIST, J. M. M. Produção e qualidade de frutos de abacaxizeiro em resposta à adubação com NPK. Revista Brasileira de Fruticultura, v. 26, n. 1, p. 155-159, abr. 2004.

TEIXEIRA, L. A. J.; SPIRONELLO, A.; FURLANI, P. R.; SIGRIST, J. M. M. Parcelamento da adubação NPK em abacaxizeiro. Revista Brasileira de Fruticultura, v. 24, n. 1, p. 219-224, abr. 2002.

VIEIRA FILHO, J. E. R.; SILVEIRA, J. M. F. J. da. Competências organizacionais, trajetória tecnológica e aprendizado local na agricultura: o paradoxo de Prebisch. Economia e Sociedade, v. 25, n. 3, p. 599-630, 2016. 